\title{
B7-H3 promotes metastasis, proliferation, and epithelial-mesenchymal transition in lung adenocarcinoma
}

This article was published in the following Dove Press journal:

OncoTargets and Therapy

\author{
Ting-Ting Yul,* \\ Tao Zhang ${ }^{2, *}$ \\ $\mathrm{Xi} \mathrm{Lu}$ \\ Ruo-Zheng Wang ${ }^{3}$ \\ 'Department of Thoracic Oncology, \\ Tumor Hospital Affiliated to Xinjiang \\ Medical University, Urumqi 8300 II, \\ People's Republic of China; \\ ${ }^{2}$ Department of Oncology, The First \\ Hospital of Lanzhou University, \\ Lanzhou 730000, People's Republic \\ of China; ${ }^{3}$ Radiation Therapy Center, \\ Tumor Hospital Affiliated to Xinjiang \\ Medical University, Urumqi 8300II, \\ People's Republic of China \\ *These authors contributed equally \\ to this work
}

Background: Lung adenocarcinoma is the most common pathological type of lung cancer. However, the mechanisms underlying its development are still poorly understood. B7-H3 was discovered as a new member of the B7 costimulatory family.

Methods: We detected the expression status of B7-H3 protein in lung adenocarcinoma tissues, and evaluated the relationship of B7-H3 expression and patients' prognosis. Then, we silenced its expression in A549 cells by transient siRNA transfection to ascertain the function of B7-H3 in lung adenocarcinoma cells. Western blotting was used to detect the expression of epithelialmesenchymal transition (EMT) related proteins.

Results: We found that B7-H3 overexpressed in lung adenocarcinoma. It is correlated with lymph node metastasis, distant metastasis, and disease stage. The Cox regression analysis showed that B7-H3 might serve as an independent prognostic marker of lung adenocarcinoma. We also found that $\mathrm{B} 7-\mathrm{H} 3$ promoted proliferation, invasion and migration of A549 cells in vitro. B7-H3 also could promote EMT progression by regulating EMT-related molecules.

Conclusion: B7-H3 is a potential target for the treatment of lung adenocarcinoma.

Keywords: lung adenocarcinoma, B7-H3, epithelial-mesenchymal transition, metastasis, proliferation

\section{Introduction}

Among malignancies, lung cancer has the highest morbidity and mortality rates, and adenocarcinoma is the most common pathological type of lung cancer. ${ }^{1}$ Lung adenocarcinoma patients with distant metastases have a 5-year survival of less than 5\% and a median survival of less than 12 months. As distant metastasis is an important cause of death in lung adenocarcinoma patients, studies on invasiveness and metastatic mechanisms are very important. Invasion and metastasis are complex, multi-step processes involving multiple genes.

B7-H3 is a type I transmembrane protein belonging to the immunoglobulin family and an important member of the B7 family of costimulatory molecules..$^{2-4}$ The B7-H3 protein is highly expressed in a variety of tumors, including those of gastric, liver, colorectal, and prostate cancers..$^{5-7}$ B7-H3 has been shown to be involved in immune escape, invasion, and metastasis of tumor cells and is closely associated with the prognosis of patients with malignancies. ${ }^{8}$ However, the mechanism by which B7-H3 is involved in tumor metastasis is unclear.

In this study, we examined the expression of B7-H3 in lung adenocarcinoma tissues and its association with the clinicopathological features of patients. Then, we
Correspondence: Ruo-Zheng Wang Radiation Therapy Center, Tumor Hospital Affiliated to Xinjiang Medical University, The No 789 of Suzhou East Road, Urumqi 8300II, Xinjiang, People's Republic of China

Tel +86099l 78I 9342

Email xjmuwrz@163.com (c)
hereby accept the Terms. Non-commercial uses of the work are permitted without any further permission from Dove Medical Press Limited, provided the work is properly attributed. For permission hereby accept the Terms. Non-commercial uses of the work are permitted without any further permission from Dove Medical Press Limited, provided the work is properly attributed. For permission 
investigated the relationship between B7-H3 and lung adenocarcinoma cell phenotypes through an in vitro experiment. Finally, we analyzed the association between B7-H3 and epithelial-mesenchymal transition (EMT) in lung adenocarcinoma.

\section{Methods}

\section{Patients and specimens}

Paraffin-embedded specimens were collected from 151 lung cancer patients treated at the Tumor Hospital of Xinjiang Medical University from March 2005 to December 2010. All patients were pathologically diagnosed with lung adenocarcinoma and complete clinical and follow-up data were available. Patients were between 35 and 78 years old (mean, 65.2 \pm 11.7 years) with 83 male and 68 female patients. These 151 patients were staged in accordance with the UICC TNM Classification (seventh edition). Paracancerous tissues, defined as tissue more than $5 \mathrm{~cm}$ away from the margin of the cancerous tissue, from 50 cases were included as controls. None of the patients were previously treated with chemotherapy, radiotherapy, or other antitumor therapies. This study, including the use of the A549 cell line, was approved and supervised by the Ethics Committee of Tumor Hospital Affiliated to Xinjiang Medical University and was performed in accordance with the Declaration of Helsinki. All study patients provided written informed consent.

\section{Cell culture}

The human lung adenocarcinoma cell line A549 was provided by the Institute of Oncology at Xinjiang Medical University. The cells were cultured in a medium containing 10\% FBS, $100 \mathrm{U} / \mathrm{mL}$ penicillin, and $100 \mu \mathrm{g} / \mathrm{mL}$ streptomycin (Thermo Fisher Scientific, Waltham, MA, USA) in a $5 \% \mathrm{CO}_{2}$ incubator at $37^{\circ} \mathrm{C}$. The medium was replaced every 3 days.

\section{Immunohistochemistry staining and evaluation}

Specimens in paraffin blocks were sectioned ( $5 \mu \mathrm{m}$ thickness), dewaxed, hydrated, and heated for antigen retrieval. Immunohistochemistry (IHC) was performed with an IHC kit (Zhong Shan Jinqiao Biotechnology Co., Beijing, People's Republic of China) according to the manufacturer's instructions. Endogenous peroxidase activity was blocked with 3\% hydrogen peroxide. After antigen retrieval, the tissue sections were incubated overnight at $4^{\circ} \mathrm{C}$ with a mouse anti-human B7-H3 antibody (1:400; Chemicon International, Temecula, CA, USA) as the primary antibody. Then, the tissue sections were incubated with a biotinylated secondary antibody and followed by a Streptavidin-HRP conjugate (Santa Cruz Biotechnology, Santa Cruz, CA, USA).

B7-H3 protein expression was observed as brownishyellow or dark brown granules in the cell membrane and cytoplasm. B7-H3 staining was assessed by a semi-quantitative double-score method as described previously. ${ }^{5-7}$ Sections were scored according to the proportion of positive cells as follows: $\leq 33 \%$ was one point, $34 \%-66 \%$ was two points, and $>66 \%$ was three points. Cells were also scored according to staining intensity: negative or weak staining (colorless or light yellow) was one point, moderate staining (yellow or brownish-yellow) was two points, and strong staining (dark brown) was three points. The final score was calculated by multiplying the two scores. A final score $\leq 3$ points was defined as low B7-H3 expression, whereas a final score $>3$ points was defined as high B7-H3 expression. All sections were scored independently by two pathologists.

\section{Cell transfection}

Endogenous B7-H3 expression in A549 cells was knocked down with siRNA with the following target sequence: siRNA1

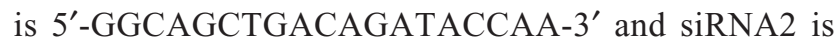
5'-GCAGCTGACAGATACCAAA-3'. Logarithmic phase cells were seeded in a six-well plate (Corning Costar, Corning, NY, USA) at $1 \times 10^{6}$ cells/well and transfected at $50 \%$ confluence. Then cells were washed three times with PBS. Serum-free medium $(200 \mu \mathrm{L})$ without double antibodies was added. Cells were transfected using Lipofectamine ${ }^{\mathrm{TM}}$ 2000 reagent (Thermo Fisher Scientific) according to the manufacturer's instructions. Cells were transfected with a scrambled siRNA as a control and untreated cells were included as a blank control. After 24 hours, transfection efficiency was assessed as GFP fluorescence under a fluorescence microscope (Olympus, Tokyo, Japan). B7-H3 expression was confirmed by Western blotting. Then, the cells were assayed for invasion and migration.

\section{Western blotting}

Total proteins were extracted from tissues to generate protein lysates. Then, equal amounts of protein $(30 \mu \mathrm{g})$ were separated by sodium dodecyl sulfate polyacrylamide gel electrophoresis (SDS-PAGE) on a 10\% gel and transferred to a polyvinylidene difluoride (PVDF) membrane. After blocking, the membranes were incubated with a mouse anti-human B7-H3 antibody. For the EMT assays, the primary antibodies were mouse anti-human E-cadherin and $\mathrm{N}$-cadherin as well 
as rabbit anti-human vimentin monoclonal antibody (Zhong Shan Jinqiao Biotechnology Company, Beijing, People's Republic of China). A GAPDH antibody (Multisciences, Hangzhou, People's Republic of China) was included as an internal reference. Then, the membranes were incubated with a goat anti-rabbit IgG secondary antibody (1:10,000). Band intensity was analyzed as OD using ImageJ (Rawak Software, http://www.rawak.de/).

\section{Cell proliferation}

Cell proliferation was determined by the 3-(4,5-dimethylthiazol2-yl)-2,5-diphenyltetrazole (MTT) assay. Briefly, logarithmic phase cells were prepared as a single cell suspension and seeded into a 96-well plate at 1,000-10,000 cells/well with $200 \mu \mathrm{L} /$ well. After 3-5 d of culture, $20 \mu \mathrm{L}$ of MTT solution (Bio-Rad, Hercules, CA, USA) was added to each well and incubated at $37^{\circ} \mathrm{C}$ for $4-6$ hours. Then, the supernatant was aspirated with a sterile pipette and $150 \mu \mathrm{L}$ of dimethylsulfoxide (DMSO; Bio-Rad) was added to each well. The absorbance was measured at $490 \mathrm{~nm}$ using a microplate reader (Bio-Rad).

\section{Invasion and migration assay}

The effects of B7-H3 on the invasion and migration of A549 cells were assessed with a transwell invasion assay. Matrigel (BD Biosciences, San Jose, CA, USA) was diluted at 1:5 in serum-free RPMI-1640 medium (Thermo Fisher Scientific) and $80 \mu \mathrm{L}$ of the diluent was added to the upper chamber of a transwell (BD Biosciences). Then, the transwell chambers were placed in 24-well plates and incubated for 5 hours at $37^{\circ} \mathrm{C}$. After 24 hours, cells were digested with $0.25 \%$ trypsin, suspended in serum-free medium, and counted. An aliquot of the cells $\left(200 \mu \mathrm{L} ; 5 \times 10^{5}\right.$ cells $\left./ \mathrm{mL}\right)$ was added to the upper chamber of a transwell with an $8-\mu \mathrm{m}$ pore membrane. RPMI-1640 medium containing $10 \%$ FBS $(600 \mu \mathrm{L})$ was added to the lower chamber and the cells were cultured for 12 hours. Then, the upper chamber of the transwell was removed and washed twice with PBS. Cells on the surface were wiped with a cotton swab, fixed in anhydrous methanol for 30 minutes, and stained with $0.4 \%$ crystal violet for 2 hours. Finally, the cells that passed through the membrane were counted under an optical microscope $(100 \times)$.

\section{Statistical analysis}

Patients were divided into two groups according to B7-H3 expression (high and low). B7-H3 expression and clinicopathologic parameters were statistically analyzed with a chi-squared test. In this study, the primary outcome was overall survival (OS). Survival analysis was performed by the Kaplan-Meier method, and the Log-rank test was used to compare the survival rates between the two groups. The Cox proportional hazards model was used to analyze the joint effect of covariates. Statistical analysis was performed using SPSS 17.0 software (SPSS Inc., Chicago, IL, USA). A $P$-value less than 0.05 was considered statistically significant.

\section{Results}

\section{Association between B7-H3 expression in lung adenocarcinoma and clinicopathological features}

IHC showed B7-H3 protein staining in the cytoplasm and cell membrane of lung adenocarcinoma cells (Figure 1A-D). The high expression rate of $\mathrm{B} 7-\mathrm{H} 3$ protein in the lung adenocarcinoma tissues was $54.96 \%(83 / 151)$, which was significantly higher than that in the paracancerous tissues $(24 \%, 12 / 50$; $\left.\chi^{2}=14.451, P<0.05\right)$. To confirm these observations, we investigated $\mathrm{B} 7-\mathrm{H} 3$ protein expression levels in 30 cases with cancer and normal paracancerous tissues by Western blot analysis. The results showed that the expression level of B7-H3 in cancer tissues was significantly higher than that of normal tissues (Figure 1E). Then, we divided the 151 patients into low and high B7-H3 expression groups and analyzed the association between $\mathrm{B} 7-\mathrm{H} 3$ protein expression and the clinicopathological features of patients with lung adenocarcinoma. We found that high B7-H3 expression was closely associated with lymph node metastasis, distant metastasis, and TNM stage $(P<0.05)$ but was not associated with age, sex, smoking history, tumor size, differentiation grade, or EGFR gene mutation status $(P>0.05)$. The above data are summarized in Table 1.

\section{Association between B7-H3 expression and prognosis of patients with lung adenocarcinoma}

To investigate the association between B7-H3 expression and the prognosis of patients with lung adenocarcinoma, we conducted a long-term follow-up of all patients. At the end of the follow-up period, we plotted survival curves. The Kaplan-Meier model showed significantly longer OS in the B7-H3 low expression group than in the high expression group (Figure 1F). We analyzed the variables that influenced OS using the Cox proportional hazards model. 

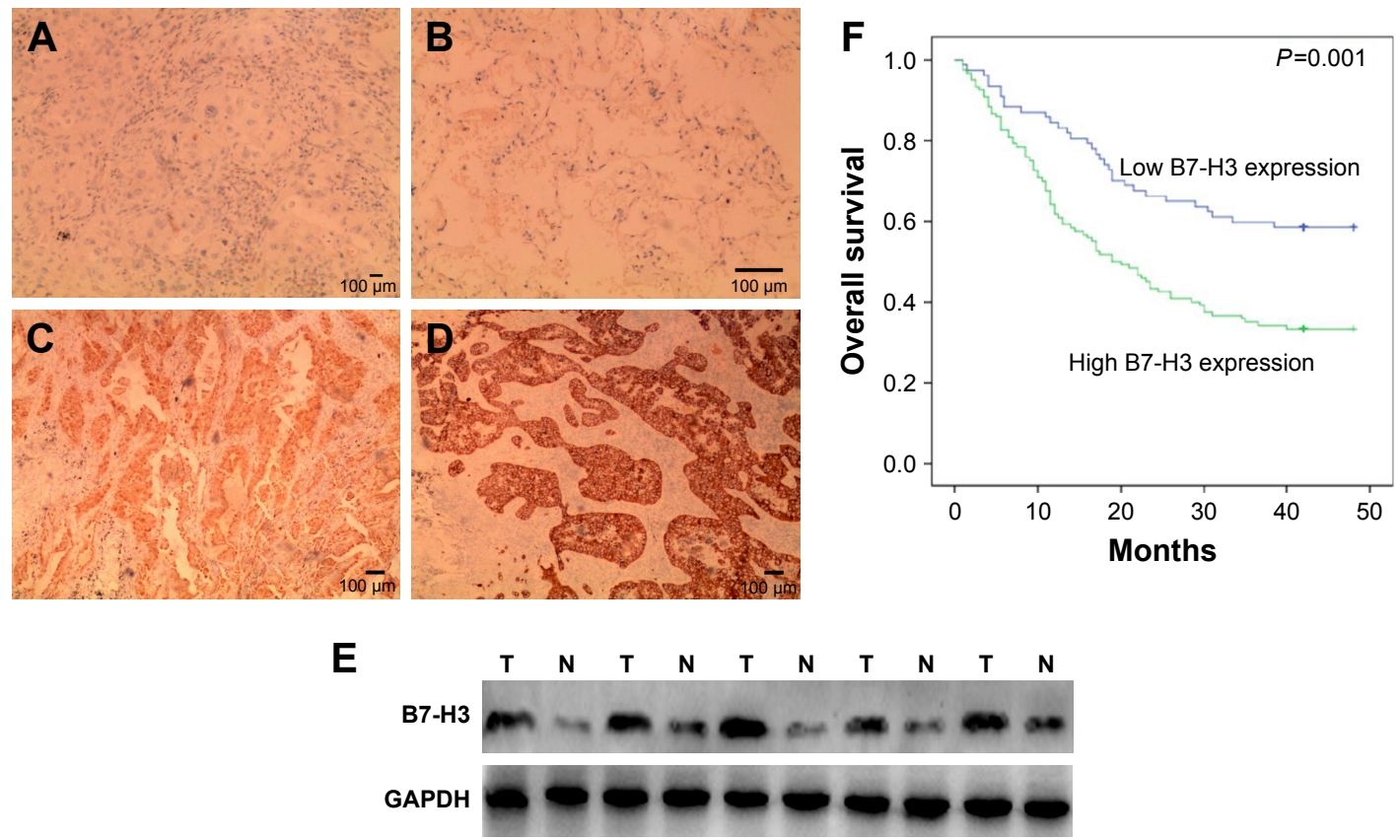

Figure I The B7-H3 expression in lung adenocarcinoma and paracancerous tissues.

Notes: (A) Low expression of B7-H3 in paracancerous tissues; (B) high expression of B7-H3 in paracancerous tissues; (C) low expression of B7-H3 in lung adenocarcinoma tissues; (D) high expression of B7-H3 in lung adenocarcinoma tissues; (E) Western blot analysis of B7-H3 expression levels in lung adenocarcinoma ( $\mathrm{T}$ ) and normal tissues (N); (F) B7-H3 expression and overall survival (OS).

Table I B7-H3 expression and clinicopathological features of patients with lung adenocarcinoma

\begin{tabular}{|c|c|c|c|c|}
\hline \multirow[t]{2}{*}{ Features } & \multirow[t]{2}{*}{$\mathbf{n}$} & \multicolumn{2}{|c|}{ B7-H3 expression } & \multirow[t]{2}{*}{$P$-value } \\
\hline & & $\begin{array}{l}\text { Low } \\
\text { expression }\end{array}$ & $\begin{array}{l}\text { High } \\
\text { expression }\end{array}$ & \\
\hline \multicolumn{4}{|l|}{ Age (years) } & $>0.05$ \\
\hline$\geq 60$ & 76 & 33 & 43 & \\
\hline$<60$ & 75 & 35 & 40 & \\
\hline \multicolumn{4}{|l|}{ Gender } & $>0.05$ \\
\hline Male & 83 & 33 & 50 & \\
\hline Female & 68 & 35 & 33 & \\
\hline \multicolumn{4}{|l|}{ Smoking } & $>0.05$ \\
\hline Yes & 78 & 35 & 43 & \\
\hline No & 73 & 33 & 40 & \\
\hline \multicolumn{4}{|l|}{ Differentiation } & $>0.05$ \\
\hline Well/moderate & 62 & 25 & 37 & \\
\hline Poor & 89 & 43 & 46 & \\
\hline \multicolumn{4}{|l|}{ Tumor size } & $>0.05$ \\
\hline$\leq 3 \mathrm{~cm}$ & 28 & 10 & 18 & \\
\hline$>3 \mathrm{~cm}$ & 123 & 58 & 65 & \\
\hline \multicolumn{4}{|c|}{ Lymph node metastasis } & $<0.05$ \\
\hline Yes & 104 & 35 & 69 & \\
\hline No & 47 & 33 & 14 & \\
\hline \multicolumn{4}{|l|}{ TNM stage } & $<0.05$ \\
\hline 1 & 21 & 17 & 4 & \\
\hline$\|$ & 42 & 23 & 19 & \\
\hline III & 38 & 13 & 25 & \\
\hline IV & 50 & 15 & 35 & \\
\hline \multicolumn{4}{|c|}{ EGFR gene mutation } & $>0.05$ \\
\hline Yes & 72 & 31 & 41 & \\
\hline No & 47 & 22 & 25 & \\
\hline Unknown & 32 & 15 & 17 & \\
\hline
\end{tabular}

Univariate analysis revealed that prognosis was closely associated with B7-H3 expression (Table 2). Higher TNM stage, positive lymph nodes, presence of distant metastasis, and high B7-H3 expression were associated with poorer prognosis. Multivariate analysis showed that the TNM stage and high B7-H3 expression were independent predictors of prognosis in patients with lung adenocarcinoma (Table 2).

\section{Transfection efficiency verification}

After transfecting A549 cells with B7-H3-siRNA or a scrambled siRNA, green fluorescence was observed in the cytoplasm. Fluorescence microscopy showed that the transfection efficiencies of the B7-H3-siRNA and scrambled siRNA, which both exceeded $75 \%$, were satisfactory (Figure 2A). B7-H3-siRNA treatment reduced the number of A549 cells, indicating that B7-H3 was involved in cell cycle progression and cell survival. To assess whether B7-H3-siRNA effectively silenced B7-H3 expression in A549 cells, total proteins were extracted from A549 cells and B7-H3 expression in the cell lysates was analyzed by Western blotting. As shown in Figure 2B, a significant decrease in B7-H3 protein expression was observed following transfection with B7-H3-siRNA as compared to the levels in untransfected cells or cells transfected with a scrambled siRNA. 
Table 2 Univariate and multivariate analysis of overall survival

\begin{tabular}{|c|c|c|c|c|}
\hline \multirow[t]{2}{*}{ Clinical parameters } & \multicolumn{2}{|l|}{ Univariate analysis } & \multicolumn{2}{|c|}{ Multivariate analysis } \\
\hline & HR (95\% Cl) & $P$-value & HR (95\% Cl) & $P$-value \\
\hline Age & $0.78 \mid(0.472-\mid .29 I)$ & 0.816 & & \\
\hline Gender & $0.932(1.35 I-4.774)$ & 0.055 & & \\
\hline Smoking & I.047 (0.7। $0-1.546)$ & 0.335 & & \\
\hline Differentiation & $1.080(0.695-1.680)$ & 0.731 & & \\
\hline EGFR gene mutation & $0.666(0.4|I-| .08 I)$ & 0.200 & & \\
\hline Lymph node metastasis & $1.907(1.136-5.398)$ & 0.023 & & \\
\hline Tumor size & $0.581(0.294-1.065)$ & 0.077 & & \\
\hline TNM stage & $2.292(I .498-3.33 I)$ & 0.000 & $2.077(1.389-3.14 I)$ & 0.000 \\
\hline B7-H3 expression & $3.167(1.616-6.327)$ & 0.001 & $3.187(1.601-6.310)$ & 0.000 \\
\hline
\end{tabular}

Abbreviation: $\mathrm{HR}$, hazard ratio.

\section{B7-H3 silencing reduced cell proliferation, invasion, and migration}

The proliferative potential of A549 cells was analyzed with the MTT assay. As shown in Figure 3A, the proliferation of B7-H3-siRNA-transfected A549 cells was significantly reduced $(P<0.05)$ compared to that of untransfected or scrambled siRNA-transfected cells. No significant difference was observed between untransfected A549 cells and scrambled siRNA-transfected cells $(P>0.05)$. A transwell invasion and migration assay was performed 48 hours after transfection to investigate the role of $\mathrm{B} 7-\mathrm{H} 3$ in lung adenocarcinoma cell invasion and migration. As shown in Figure 3B, the number of invading or migrating B7-H3-siRNA-transfected
A549 cells was significantly lower $(P<0.05)$ than the number of untransfected and scrambled siRNA-transfected cells. There was no significant difference between scrambled siRNA-transfected and untransfected control cells $(P>0.05)$. These data indicate that silencing B7-H3 through transient transfection with a B7-H3-siRNA inhibits the invasion and migration of lung adenocarcinoma cells.

\section{Role of B7-H3 in EMT of lung adenocarcinoma cells}

B7-H3 expression in lung adenocarcinoma A549 cells was silenced by transfection with a B7-H3-specific siRNA. After transfection, B7-H3 protein expression in A549 cells was
A

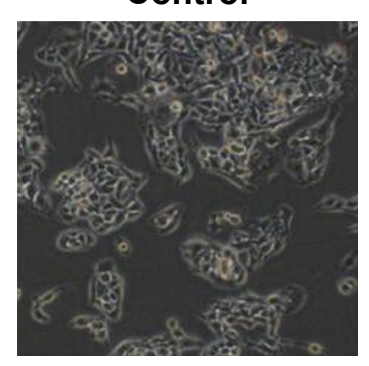

Scrambled siRNA

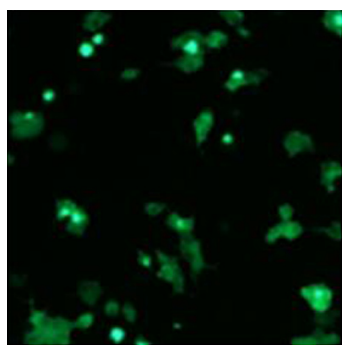

B7-H3-SiRNA1

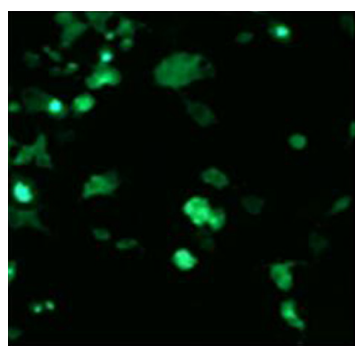

\section{B7-H3-siRNA2}

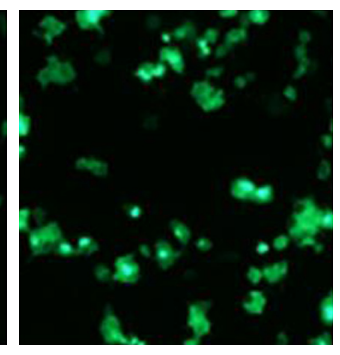

B
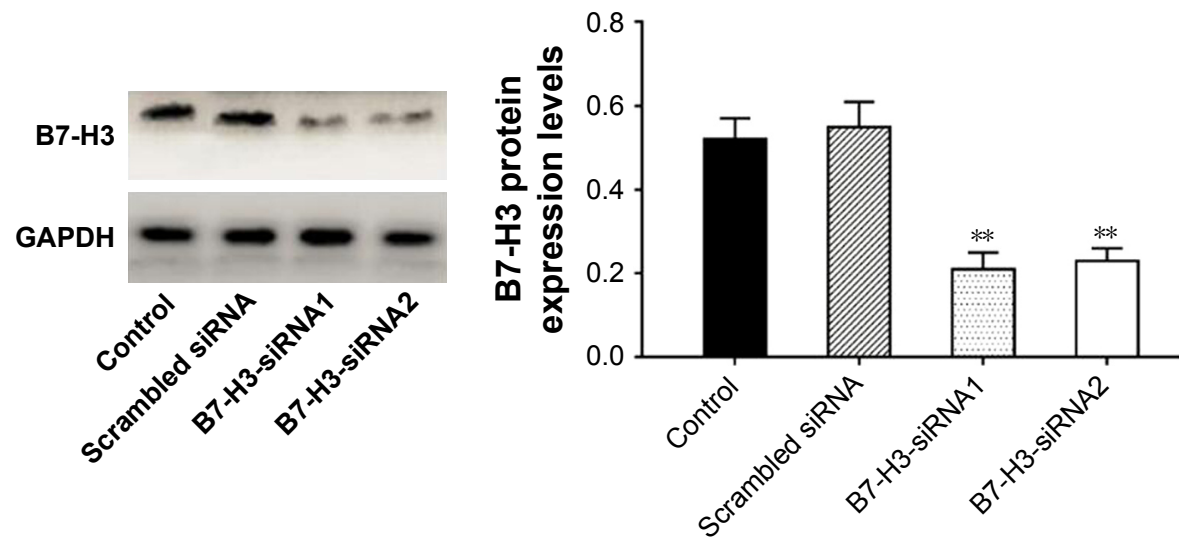

Figure 2 (A) The transfection efficiencies observed using fluorescence microscopy; (B) B7-H3 expression levels detected in A549 cell lines by Western blot. Note: $* * P<0.01$. 

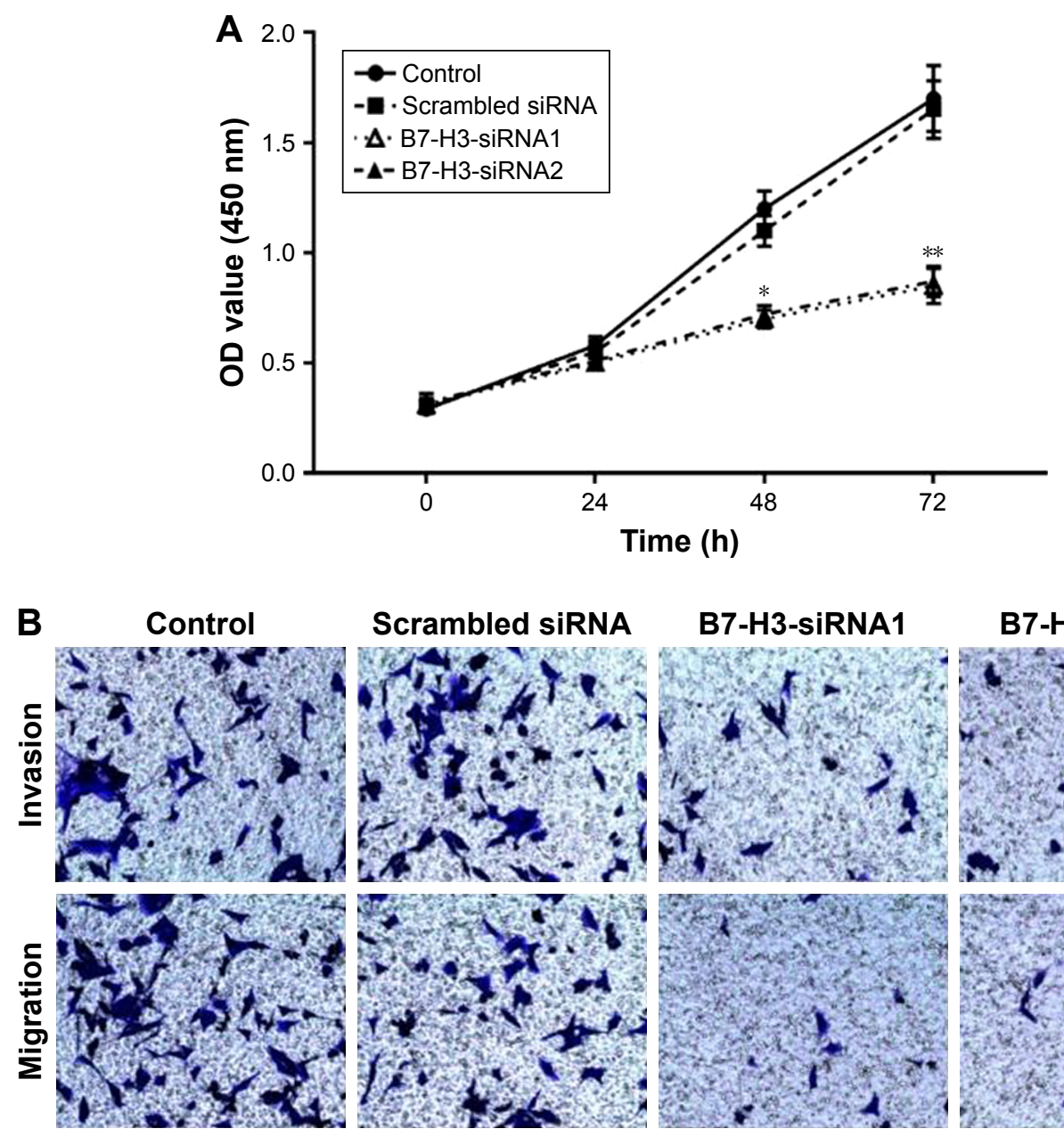

B7-H3-siRNA2

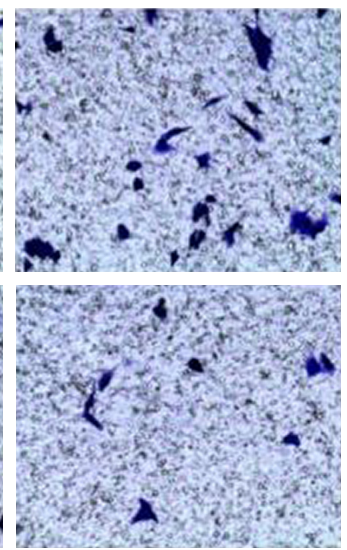

Figure 3 Silencing B7-H3 reduces proliferation, invasion and migration of NSCLC cells.

Notes: (A) Viability measured by MTT assay in A549 cells; (B) transwell invasion and migration assay with control and B7-H3 siRNA-transfected A549 cells. *P $<0.05$; $* * P<0.01$.

Abbreviation: NSCLC, non-small cell lung carcinoma.

markedly downregulated. To assess the effect of B7-H3 on EMT, we analyzed the changes in EMT-related protein expression in A549 cells before and after B7-H3 silencing and found that E-cadherin protein was significantly upregulated while $\mathrm{N}$-cadherin and vimentin were significantly downregulated $(P<0.05$, Figure 4$)$. This suggests that B7-H3 downregulation may inhibit EMT in lung adenocarcinoma cells.

\section{Discussion}

In 2001, B7-H3 was identified as a new member of the B7 costimulatory family. This molecule was cloned from a human dendritic cell cDNA library and analysis showed that it shared $20 \%-27 \%$ amino acid sequence identity with other B7 family members. ${ }^{8,9}$ Research has shown that B7-H3 facilitates tumor cell immune surveillance evasion by inhibiting $\mathrm{T}$ cell-mediated cellular immunity. B7-H3 is abnormally expressed in gastric, colorectal, liver, and pancreatic cancers. ${ }^{710-12}$ B7-H3 has been shown to be involved in tumorigenesis and cancer development through immune and non-immune pathways. Existing evidence indicates that B7-H3 is highly expressed in non-small-cell lung cancer (NSCLC) and is closely associated with prognosis in NSCLC patients. In this study, we confirmed that B7-H3 was highly expressed in lung adenocarcinoma specimens, which is similar to what was observed in previous studies.

The major challenge in lung cancer treatment is metastasis, which is a continuous and complicated multistep process. In lung adenocarcinoma, distant metastasis can occur in the early stages of the disease. $\mathrm{B} 7-\mathrm{H} 3$ has been shown to be involved in the metastasis of various tumors. Dai et a ${ }^{13}$ found that inhibition of B7-H3 expression in gastric cancer reduced cell migration and invasion by up to $50 \%$ and significantly reduced bone metastasis in tumor-bearing mice. In addition, 

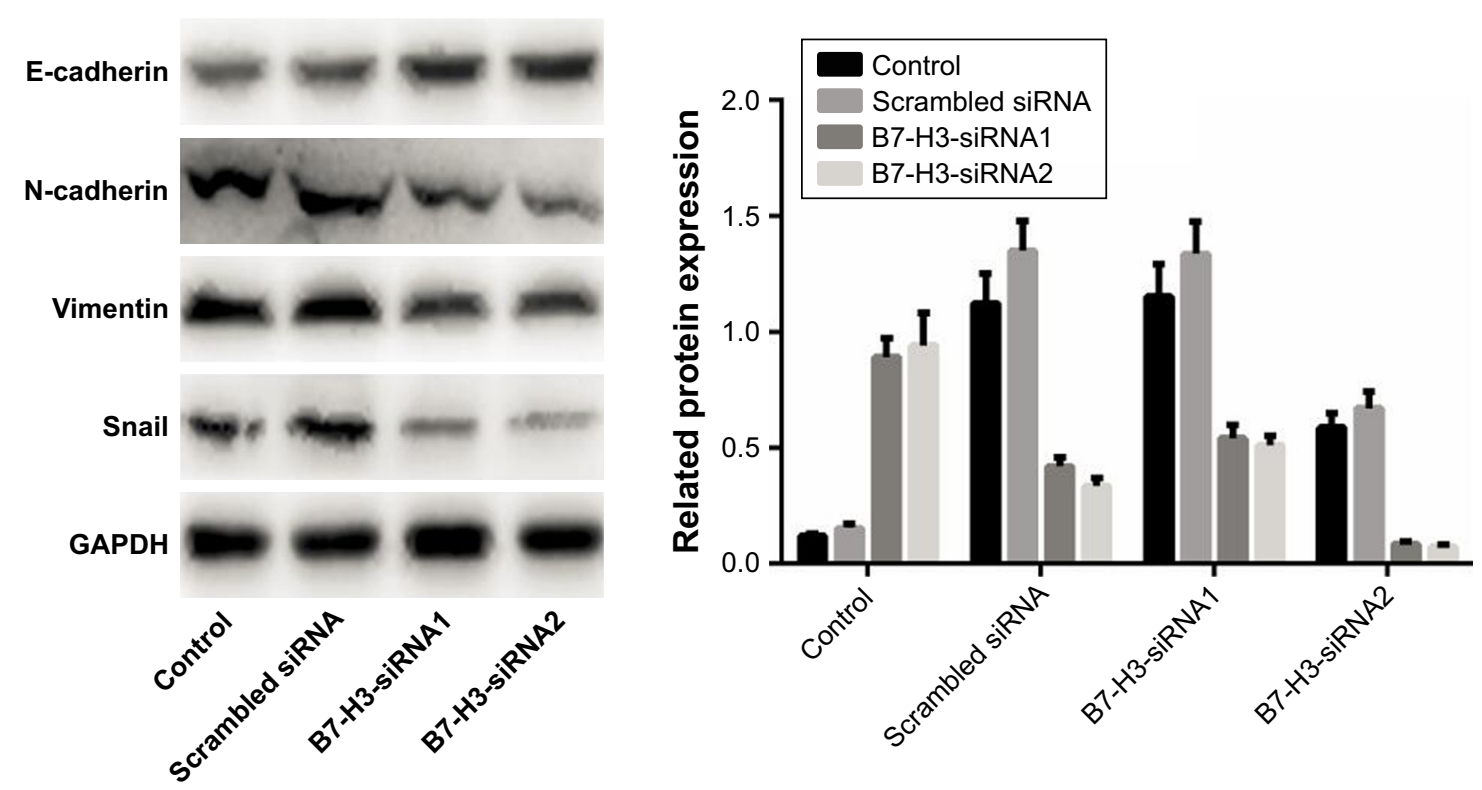

Figure $4 \mathrm{~B} 7-\mathrm{H} 3$ regulates the protein expression levels of E-cadherin, $\mathrm{N}$-cadherin and vimentin.

B7-H3 expression in human pancreatic cancer tissues has been shown to be closely related to lymph node metastasis. ${ }^{14}$ High expression of B7-H3 mRNA in prostate cancer is both significantly positively correlated with metastasis and associated with poorer prognosis. ${ }^{15}$ Here, we showed, through long-term follow-up, that lung adenocarcinoma patients with high B7-H3-expressing tumors had shorter survival and worse prognosis than wild-type controls. Cox regression model analysis showed that B7-H3 was a marker of prognosis in patients with lung adenocarcinoma. We silenced B7-H3 expression in the A549 cell lines and showed that silencing B7-H3 remarkably inhibited the proliferation, invasion, and migration of lung adenocarcinoma cells. These results were consistent with clinical findings. ${ }^{13-20}$

The mechanism by which B7-H3 is involved in the metastasis of lung adenocarcinoma is not fully understood. However, it is known that EMT is a key step in metastasis. During EMT-induced invasion and metastasis of tumor cells, the cells lose polarity, reduce contact with the surrounding matrices, and show markedly enhanced migration and motility, ultimately resulting in the formation of metastatic lesions. ${ }^{21-23}$ EMT causes epithelial cells to lose polarity, separate from the surrounding epithelial tissues, and move to other locations. There are no previous reports on the involvement of B7-H3 in the EMT of lung adenocarcinoma. Here, we analyzed the expression of EMT-related molecules in A549 cells by Western blotting after silencing B7-H3 expression. The results showed that the epithelial cell marker
E-cadherin was upregulated, whereas the mesenchymal cell markers $\mathrm{N}$-cadherin and vimentin were downregulated. Presumably, B7-H3 promotes the EMT progression of lung adenocarcinoma cells. This suggests that B7-H3 promotes lung adenocarcinoma metastasis, at least in part, by regulating the EMT of tumor cells. ${ }^{23}$

In summary, B7-H3 can promote EMT progression by regulating EMT-related molecules, thereby increasing the malignant behavior of lung adenocarcinoma cells. Therefore, B7-H3 is a potential target for the treatment of lung adenocarcinoma. However, the pathways and mechanism by which B7-H3 promotes the development of lung adenocarcinoma are still unclear and should be elucidated in future studies.

\section{Acknowledgment}

This study was supported by Xinjiang Uygur Autonomous Region Natural Science Foundation of China (grant no 2017D01C377).

\section{Disclosure}

The authors report no conflicts of interest in this work.

\section{References}

1. Torre LA, Bray F, Siegel RL, et al. Global cancer statistics, 2012. CA Cancer J Clin. 2015;65(2):87-108.

2. Vigdorovich V, Ramagopal UA, Lázár-Molnár E, et al. Structure and $\mathrm{T}$ cell inhibition properties of B7 family member, B7-H3. Structure. 2013;21(5):707-717.

3. Gonzalez DM, Medici D. Signaling mechanisms of the epithelialmesenchymal transition. Sci Signal. 2014;7(344):re8. 
4. Ye Y, Liu P, Wang Y, et al. Neurotensin, a novel messenger to cross-link inflammation and tumor invasion via epithelial-mesenchymal transition pathway. Int Rev Immunol. 2016;35(4):340-350.

5. Wang L, Kang FB, Shan BE. B7-H3-mediated tumor immunology: Friend or foe? Int J Cancer. 2014;134(12):2764-2771.

6. Leung J, Suh WK. The CD28-B7 family in anti-tumor immunity: emerging concepts in cancer immunotherapy. Immune Netw. 2014;14(6): 265-276.

7. Wu S, Zhao X, Wu S, et al. Overexpression of B7-H3 correlates with aggressive clinicopathological characteristics in non-small cell lung cancer. Oncotarget. 2016;7(49):81750-81756.

8. Chockley PJ, Keshamouni VG. Immunological consequences of epithelial-mesenchymal transition in tumor progression. JImmunol. 2016; 197(3):691-698

9. Lou Y, Diao L, Cuentas ER, et al. Epithelial-mesenchymal transition is associated with a distinct tumor microenvironment including elevation of inflammatory signals and multiple immune checkpoints in lung adenocarcinoma. Clin Cancer Res. 2016;22(14):3630-3642.

10. Qin X, Zhang H, Ye D, Dai B, Zhu Y, Shi G. B7-H3 is a new cancerspecific endothelial marker in clear cell renal cell carcinoma. Onco Targets Ther. 2013;6:1667-1673.

11. Schneider T, Hoffmann H, Dienemann H, et al. Non-small cell lung cancer induces an immunosuppressive phenotype of dendritic cells in tumor microenvironment by upregulating B7-H3. J Thorac Oncol. 2011;6(7):1162-1168.

12. Boland JM, Kwon ED, Harrington SM, et al. Tumor B7-H1 and B7-H3 expression in squamous cell carcinoma of the lung. Clin Lung Cancer. 2013;14(2):157-163.

13. Dai W, Shen G, Qiu J, Zhao X, Gao Q. Aberrant expression of B7-H3 in gastric adenocarcinoma promotes cancer cell metastasis. Oncol Rep. 2014;32(5):2086-2092.
14. Xu H, Chen X, Tao M, et al. B7-H3 and B7-H4 are independent predictors of a poor prognosis in patients with pancreatic cancer. Oncol Lett. 2016;11(3):1841-1846.

15. Zhao X, Li DC, Zhu XG, et al. B7-H3 overexpression in pancreatic cancer promotes tumor progression. Int J Mol Med. 2013;31(2):283-291.

16. Jin $\mathrm{Y}$, Zhang $\mathrm{P}, \mathrm{Li} \mathrm{J}$, et al. B7-H3 in combination with regulatory $\mathrm{T}$ cell is associated with tumor progression in primary human non-small cell lung cancer. Int J Clin Exp Pathol. 2015;8(11):13987-13995.

17. Feng W, Yu Q, Zhang B, Zhang JB, Zhang MM. Expression and significance of CO signaling molecule B7-H3 in human lung adenocarcinoma. Guang Dong Med J. 2015;6(162):1869-1871.

18. Mao Y, Li W, Chen K, et al. B7-H1 and B7-H3 are independent predictors of poor prognosis in patients with non-small cell lung cancer. Oncotarget. 2015;6(5):3452-3461.

19. Inamura K, Yokouchi Y, Kobayashi M, et al. Tumor B7-H3 (CD276) expression and smoking history in relation to lung adenocarcinoma prognosis. Lung Cancer. 2017;103:44-51.

20. Li Y, Zhang J, Han S. et al. B7-H3 promotes the proliferation, migration and invasiveness of cervical cancer cells and is an indicator of poor prognosis. Oncol Rep. 2017;8(38):1043-1050.

21. Huang L, Wu RL, Xu AM, Rl W, Am X. Epithelial-mesenchymal transition in gastric cancer. Am J Transl Res. 2015;7(11):2141-2158.

22. Peng Z, Wang CX, Fang EH, Wang GB, Tong Q. Role of epithelialmesenchymal transition in gastric cancer initiation and progression. World J Gastroenterol. 2014;20(18):5403-5410.

23. Thiery JP, Sleeman JP. Complex networks orchestrate epithelialmesenchymal transitions. Nat Rev Mol Cell Biol. 2006;7(2):131-142.
OncoTargets and Therapy

\section{Publish your work in this journal}

OncoTargets and Therapy is an international, peer-reviewed, open access journal focusing on the pathological basis of all cancers, potential targets for therapy and treatment protocols employed to improve the management of cancer patients. The journal also focuses on the impact of management programs and new therapeutic agents and protocols on

\section{Dovepress}

patient perspectives such as quality of life, adherence and satisfaction The manuscript management system is completely online and includes a very quick and fair peer-review system, which is all easy to use. Visit http://www.dovepress.com/testimonials.php to read real quotes from published authors. 